\title{
Microbial fuel cell (MFC) in treating spent caustic wastewater
}

Norsafiah Fazli; Noor Sabrina Ahmad Mutamim; Mohd Faizal Ali

Department of Chemical Engineering, Faculty of Chemical and Natural Resources Engineering, Universiti Malaysia Pahang, LeburayaTun Razak, 26300 Gambang, Kuantan, Pahang, Malaysia

\begin{abstract}
Some of the major problems encountered by the world are water pollution and natural resources depletion. One of the major factors which contribute to water pollution is insufficiently treated wastewater whereas the depletion of natural resources is due to the dependability of the fossil fuel as the main energy source. Both of these issues show the world urgently required an effective technology of wastewater treatment and energy recovery. Microbial Fuel Cell (MFC) is a treatment method that can achieve the needs of effective treatment of wastewater and energy recovery simultaneously. As mentioned, insufficiently treated wastewater is one of the main causes which contributes to water pollution. Spent caustic wastewater is one of the industrial wastewater that is difficult to be treated, handled and disposed due to its noxious properties. Existing treatment method of treating spent caustic wastewater are limited by low efficiency. However, by applying MFCs, organic and inorganic contaminants are oxidized by biomass and produce electron that is transferred to electrode. The movement of the electron from anode to cathode generates electricity and turns MFC into a treatment method that able to provide both wastewater treatment and energy production. This article presents a review of spent caustic wastewater and its existing treatment method as well as the MFC researches in terms of its configuration and factors affecting its performance.
\end{abstract}

\section{KEYWORDS:}

Wastewater treatment; energy recovery; spent caustic wastewater; Microbial Fuel Cell 